\title{
Association of Vitamin D Receptor Gene Polymorphisms and Type1 Diabetes in an Egyptian Population
}

Mona Gamal Elgazzaz ${ }^{\star}$, Eman Abd-ElMoemen Mohammed ${ }^{1}$, Hoda Ahmed Atwa $^{2}$ and Fouad Mohamed Badr ${ }^{1}$

${ }^{1}$ Genetics Unit, Department of Histology and Cell Biology, Ismailia, Egypt

${ }^{2}$ Department of Pediatrics, Faculty of Medicine, Suez Canal University, Ismailia, Egypt

\begin{abstract}
Aim and background: Vitamin $D$ is known for its immune modulatory functions and its role in normal insulin secretion. Vitamin $D$ acts via vitamin $D$ receptor gene (VDR). The study was conducted to assess the relationship between Apa I and Taq I restriction site polymorphisms of vitamin D receptor gene and type1 diabetes in an Egyptian
\end{abstract} population.

Subjects and Methods: One hundred Egyptian participants (1-20 years old) of both sexes were recruited in this study. Fifty of them were type 1 diabetes patients and the other fifty were control non diabetic subjects. Apa I and Taq I variations were tested using Polymerase Chain Reaction and Restriction Fragment Length Polymorphism.

Results: Genetic analysis revealed that $A A$ and $T t$ genotypes were predominant in the two study groups with higher frequency among patients group, whereas, aa and tt genotypes were predominant among controls $(14 \%$ and $10 \%$, respectively). Combined genotypes $A A T t, A A t t$ and aaTT were significantly more frequent in controls ( $\mathrm{P}$ value of odds ratio $0.032,0.033,0.002$, respectively). The haplotype $A T$ was more frequent among diabetics $(41 \%)$, whereas, haplotypes $A t$ and aT were more frequent in control group (39\%, 29\%, respectively). Linkage analysis of Apa I and Taq I markers showed strong linkage disequilibrium between two markers $\left(D^{\prime}=1\right)$.

Conclusion: Apa I and Taq I VDR gene polymorphisms have an association with T1D and may predispose to the risk of T1D affection. While, genotypes AATt, AAtt and aaTT and haplotypes $A t$ and aT seem to have a possible protective effect against T1D.

Keywords: Genomic DNA; Single nucleotide polymorphism; Type 1 diabetes mellitus; Vitamin D receptor gene

\section{Introduction}

Type 1 diabetes (T1D) is an immune-mediated disorder where clinical disease develops as a result of interactions between genetic and environmental factors. T-lymphocytic infiltration occurs first in pancreatic islets causing insulitis then destruction of beta cells [1].

In 2013, The International Diabetes Federation stated that Egypt has the largest contribution to the total number of estimated childhood type 1 diabetes cases for Eastern Mediterranean and Middle East region which accounts for almost a quarter of the region's total number. The incidence of type 1 diabetes is reported as 8 per 100,000 populations per year for those aged 14 years and under [2].

Type 1 diabetes is a multifactorial disease with strong genetic component. The major T1D susceptibility locus maps to the HLA class II genes and accounts for up to $30 \%-50 \%$ of genetic T1D risk. Other non-HLA T1D loci were known to produce smaller effects on disease risk compared to HLA genes. These loci include insulin gene (INS), cytotoxic T-lymphocyte associated protein 4 (CTLA4) genes and protein tyrosine phosphatase non receptor type 22 (PTPN22) gene [3].

The involvement of vitamin $\mathrm{D}$ in the etiology of both type 1 and type 2 diabetes has been suggested. Vitamin D compounds are known to suppress $\mathrm{T}$-cell activation by binding to the vitamin $\mathrm{D}$ receptor (VDR). Polymorphisms of the VDR gene are likely to be related to T-cell mediated autoimmune disease [4].

Vitamin D is a fat-soluble vitamin that plays an important role in bone metabolism and seems to have some anti-inflammatory and immune-modulating properties [5]. Most of these biological actions of vitamin $\mathrm{D}$ are considered to be exerted through the nuclear vitamin $\mathrm{D}$ receptor (VDR)-mediated control of target genes [6].
The VDR gene, located on chromosome 12q13.11 encodes a polypeptide that binds 1, 25-dihydroxy-calciferol and interacts with target nuclei to produce a variety of effects [7]. Several major polymorphic sites have been described within the VDR gene. FokI in exon 2, Bsm I and Apa I both in intron 10 and Taq I in exon 11 are the four common single nucleotide polymorphisms (SNPs) for the VDR gene [8].

The Apa I (rs7975232) is located in intron 10. Apa I is a Restriction Fragment Length Polymorphism (RFLP) showing Guanine to Thymine nucleotide substitution. Chromosome position of the SNP is 47845054, and position of the SNP in the VDR gene is 64978, located on the reverse strand [9].

Taq I polymorphism (rs731236) is a Restriction Fragment Length Polymorphism (RFLP) in exon 11 of the VDR gene. Taq I is a thymine to cytosine polymorphism. SNP lies on the forward strand of the VDR gene on position 65058 [10].

The conflicting results and unclear associations between VDR gene polymorphisms and T1D in addition to unavailable data in Egypt have encouraged us to examine two of the restriction site polymorphisms of VDR gene which are Apa I and Taq I in an Egyptian population.

*Corresponding author: Dr. Mona Gamal Elgazzaz, Genetics Unit, Department
of Histology and Cell Biology, Ismailia, Egypt, Tel: +201112518610; E-mail: monaelgazzaz@med.suez.edu.eg

Received July 26, 2016; Accepted July 30, 2016; Published August 08, 2016

Citation: Elgazzaz MG, Mohammed EAE, Atwa HA, Badr FM (2016) Association of Vitamin D Receptor Gene Polymorphisms and Type1 Diabetes in an Egyptian Population. Mol Biol 5: 171. doi:10.4172/2168-9547.1000171

Copyright: (c) 2016 Elgazzaz MG, et al. This is an open-access article distributed under the terms of the Creative Commons Attribution License, which permits unrestricted use, distribution, and reproduction in any medium, provided the original author and source are credited. 


\section{Subjects and Methods}

\section{Subjects}

The study was conducted on fifty T1D Egyptian patients with median age 8.5 (5-12.7) years. Disease onset ranged from 1 to 5 years old. Fifty healthy participants matching in age and gender were recruited to the study. T1D patients with chronic illnesses or syndromes were excluded. The study was carried out upon attendants of The Pediatrics Clinic, Insurance Hospital, Ismailia. Individuals enrolled in the study were subjected to a structured interview together with their parents. A questionnaire was given to each parent and filled in. A short account about the aim of study and the procedures done were explained for each participant. The study was conducted in accordance with the guidelines in the Declaration of Helsinki and was approved by the Ethical Committee of the Faculty of Medicine, Suez Canal University (research approval No. ID 1662014). An informed consent was obtained from all participants.

\section{Genotyping}

Molecular analysis of Apa I and Taq I restriction site polymorphisms of vitamin D receptor gene was done to every participant. Five $\mathrm{ml}$ of venous blood was collected from each individual in a heparinized tube. Blood samples were either freshly used for DNA extraction or stored at $-20^{\circ} \mathrm{C}$ for later use. DNA was extracted using QIAamp DNA Blood Mini Spin Column Kits (Germany), catalog no. 51104. Amplification of target DNA sequence of VDR gene was done using 96-well Thermal Cycler, (Applied Biosystems Veriti (USA) P/N: 43757860). Resultant amplicon is represented in Figure 1. Figure 2 shows a demonstration using bioinformatics tools of amplified DNA segment and site for primers binding to the VDR segment [11-13].

PCR was done using $12.5 \mu$ l of Master Mix, GoTaq Green Master Mix, (Promega (USA) Catalog no. M7112). Then adding $1 \mu \mathrm{l}$ each of forward primers and reverse primers together with 1-5 $\mu$ l of extracted DNA samples at concentration $200 \mathrm{ng} / \mu \mathrm{l}$. Apa I and Taq I were targeted by common Apa/ Taq forward and reverse primers [14]. PCR conditions are shown in Table 1. For testing PCR amplification of the target DNA segment of VDR gene, gel electrophoresis was done using $2 \%$ agarose gel.

Amplified DNA sequences were digested separately by Apa I Restriction Enzyme, (FastDigestApa I, Fermentas (USA), catalog no. FD1414) and Taq I Restriction Enzyme, (FastDigest Taq I, Fermentas (USA), catalog no. FD0674). For each SNP, $17 \mu$ l of nuclease free water, $2 \mu \mathrm{l}$ of buffer, $1 \mu \mathrm{l}$ of enzyme and $10 \mu \mathrm{l}$ of PCR product were added. Tubes digested by Apa I were incubated at $37^{\circ} \mathrm{C}$ for $20 \mathrm{~min}$, while tubes digested by Taq I were incubated at $65^{\circ} \mathrm{C}$ for $5 \mathrm{~min}$. Digested DNA fragments were electrophoresed on $2.5 \%$ agarose gel and finally viewed under ultraviolet transilluminator (Figures 3 and 4).

Depending on the presence or absence of Apa I restriction site, alleles found are AA (745 bp), aa (217 and 528 bp and Aa 745, 217 and $528 \mathrm{bp}$ ). For Taq I, alleles are TT (494 and $251 \mathrm{bp),} \mathrm{tt} \mathrm{of} \mathrm{(294,} 200$ and $251 \mathrm{bp}$ ) and $\mathrm{Tt}$ (494, 294, 200 and $251 \mathrm{bp}$ ). Upper case letters denote the absence of restriction site and lower case letters denote presence of restriction site.

\begin{tabular}{|c|c|c|c|c|c|}
\hline Stage & $\begin{array}{c}\text { Initial } \\
\text { Denaturation }\end{array}$ & $\begin{array}{c}\text { Subsequent } \\
\text { Denaturation }\end{array}$ & Annealing & Extension & $\begin{array}{c}\text { Final } \\
\text { Extension }\end{array}$ \\
\hline Temperature & $95^{\circ} \mathrm{C}$ & $95^{\circ} \mathrm{C}$ & $67^{\circ} \mathrm{C}$ & $72^{\circ} \mathrm{C}$ & $72^{\circ} \mathrm{C}$ \\
\hline Duration & $2 \mathrm{~min}$ & $1 \mathrm{~min}$ & $1 \mathrm{~min}$ & $1 \mathrm{~min}$ & $5 \mathrm{~min}$ \\
\hline \multicolumn{5}{c}{ Table 1: PCR conditions. } \\
\hline \multicolumn{5}{c}{} \\
\hline
\end{tabular}

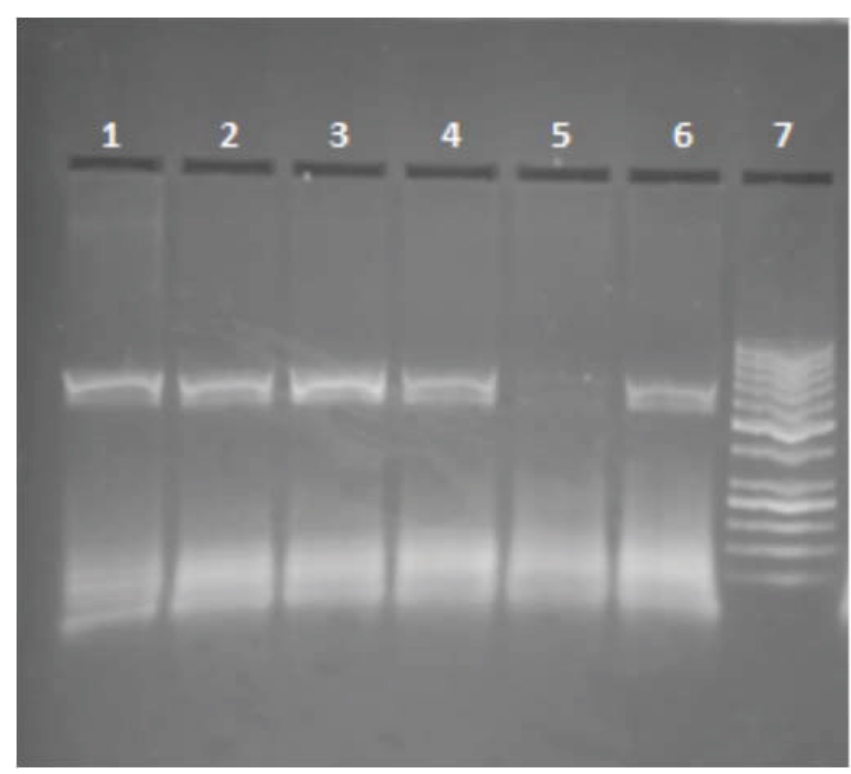

Figure 1: Gel Electrophoresis Of PCR Products. Numbers refer to lanes. Lane 7 shows 50 bp DNA marker, the upper bright DNA band in the marker is $500 \mathrm{bp}$ in length, the lower bright band is $250 \mathrm{bp}$. Lanes $1-6$ show amplified DNA segments of length $745 \mathrm{bp}$.

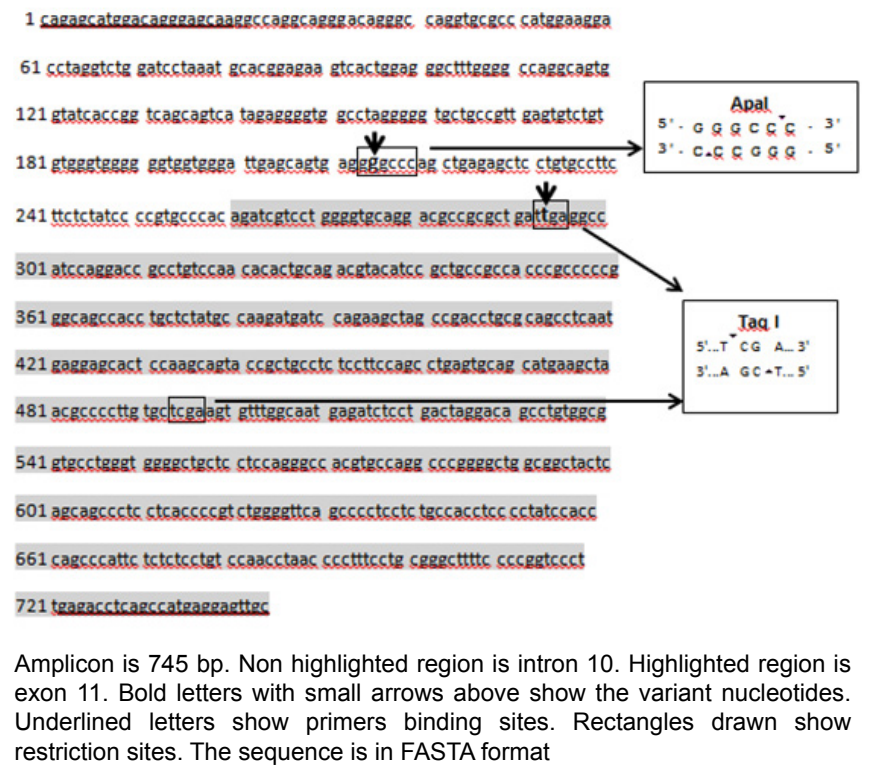

Figure 2: Amplified VDR gene segment.

\section{Statistical analysis}

Data were managed using Microsoft ${ }^{\circ}$ Excel 2010 and "Statistical Package for Social Sciences (SPSS) for windows", version 20.0. Descriptive statistics were represented as median and ranges from the $25^{\text {th }}$ to the $75^{\text {th }}$ percentile for non-parametric variables calculated using Minitab 17 version 17.2.1. Qualitative variables were described in percentage. Chi square and Kruskal Wallis tests were used.

The allele frequency within each group was determined as the number of occurrences of an individual allele divided by the total number of alleles. The carriage rate was calculated as the number of 


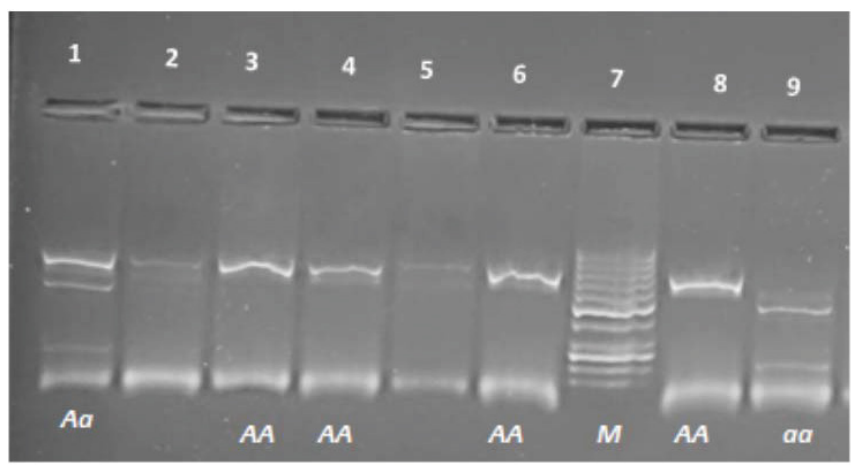

Figure 3: Gel Electrophoresis of Apa I Samples. Number of lanes is shown on top of the image. Lane 7 shows 50 bp DNA marker, the upper bright DNA band in the marker is $500 \mathrm{bp}$ in length, the lower bright band is $250 \mathrm{bp}$. Lane 1 shows 3 bands of lengths 745,528 and $217 \mathrm{bp}$, diagnosed as heterozygote "Aa". Lanes $3,4,6$ and 8 show one band of length $745 \mathrm{bp}$, diagnosed as homozygote " $A A$ ". Lane 9 shows 2 bands of lengths 528 and $217 \mathrm{bp}$, diagnosed as homozygote "aa".

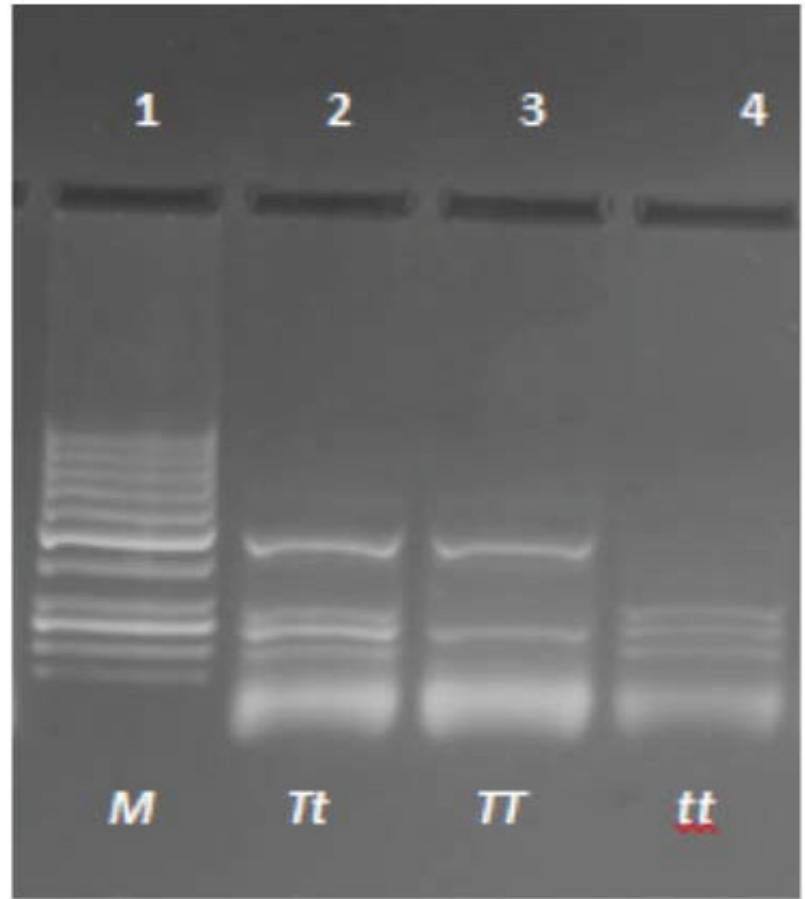

Figure 4: Gel Electrophoresis of Taq I Samples. Number of lanes is shown on top of the image. Lane 1 shows 50 bp DNA marker " $M$ ", the upper bright DNA band in the marker is $500 \mathrm{bp}$ in length, the lower bright band is $250 \mathrm{bp}$. Lane 2 shows 4 DNA bands of lengths 494, 294, 251 and 200bp, diagnosed as heterozygote " $T$ ". Lane 3 shows 2 bands at 494 and $251 \mathrm{bp}$, diagnosed as homozygote "TT". Lane 4 shows 3 bands at 294, 251 and 200bp, diagnosed as homozygote " $t t$ ".

individuals carrying at least one of the investigated alleles divided by the total number of individuals in each group $[15,16]$.

Hardy-Weinberg equilibrium (HWE) was used to calculate the expected genotype frequencies among patient and control groups [17].

Differences in genotypic and allelic distribution of VDR polymorphisms between patients and controls were determined by Pearson Chi-square $\left(\chi^{2}\right)$. The $P$ value less than 0.05 was regarded as statistically significant. Haplotype analysis was performed by CHAPLIN 1.2.3 software. Pairwise linkage disequilibrium (LD) between the VDR gene polymorphisms was computed and LD plots were constructed using Haploview software, version 4.2.

\section{Results}

Genotype frequencies of Apa I and Taq I among patients and controls are shown in Table 2. Regarding Apa I genotype, $A A$ genotype is predominant is both diabetic (60\%) and control groups (56\%). Genotype aa was the least frequent in both groups, however, $a a$ genotype was observed to have increased frequency in control group (14\%) than patients group (4\%). Differences in distribution are statistically insignificant. In Taq I genotype, the frequency of $T t$ was the highest among the two groups, while genotype $t t$ was the lowest. TT genotype showed the same distribution among patients and controls (36\%). Tt genotype showed increased distribution among patients while $t t$ showed increased distribution among controls. Chi square test and odds ratio $(\mathrm{OR})$ test were done with no significant differences. $\mathrm{P}$ value for Hardy Weinberg Equilibrium is calculated for Apa I and Taq I genotypes (Table 2). All results are in equilibrium with Hardy Weinberg.

Distribution of Apa I and Taq I genotypes and alleles according to gender, family history or age at diagnosis in both patients and controls revealed non-significant results. In addition, distribution of haplotypes and genotype combinations according to gender and family history in patient and control groups showed statistically insignificant differences.

The frequency of Apa I alleles $A$ versus $a$ represented $78 \%$ and $71 \%$ versus $22 \%$ and $29 \%$ in patients and controls respectively. Taq I alleles showed also no significant difference between diabetic and control groups ( $P=0.25$ ), where $T$ versus $t$ represented $63 \%$ and $61 \%$ versus $37 \%$ and $39 \%$ patients and controls $(P=0.77)$, respectively (Figure 5$)$. Odds ratios didn't show increased risk of any allele to acquire disease than the control. In Apa I alleles, OR of $a$ allele (CI 95\%) was 0.69 (0.36-1.31) and OR of $t$ allele (CI 95\%) of Taq I variant was 0.91 (0.51-1.62). $P$ values of OR tests are greater than 0.05 .

$A$ allele showed higher rate of carriage in the patients group (78\%) than in the control group (71\%). However there was no significant difference between diabetic and control group regarding the carriage of $A$ allele. $T$ allele also showed higher rate in the diabetic group that was not significant as well (Table 3 ).

Haplotype analysis showed that the three haplotypes aT, At and $A T$ were found among the diabetic and control groups in frequencies shown in Table 4. Haplotype "at" was absent among patient and control groups. Haplotype $A T$ was found in $41 \%$ of patients whereas;

\begin{tabular}{|c|c|c|c|c|c|}
\hline Variables & $\begin{array}{c}\text { Patients } \\
(\mathbf{n = 5 0 )} \\
\mathbf{n}(\mathbf{\%})\end{array}$ & $\begin{array}{c}\text { Controls(n=50) } \\
\mathbf{n}(\mathbf{\%})\end{array}$ & $\mathbf{X}^{\mathbf{2}}$ & P value & $\begin{array}{c}\text { OR } \\
\mathbf{( 9 5 \%} \mathbf{C l})\end{array}$ \\
\hline Apa I Genotype & & & & & \\
\hline$A A$ & $30(60)$ & $28(56)$ & 3.1 & 0.2 & Reference \\
\hline$A a$ & $18(36)$ & $15(30)$ & & & $1.12(0.47-2.63)$ \\
\hline$a a$ & $2(4)$ & $7(14)$ & & & $0.26(0.05-1.39)$ \\
\hline$P_{\text {HWE }}$ & 0.72 & 0.054 & & & \\
\hline Taq I Genotype & & & & & \\
\hline$T T$ & $18(36)$ & $18(36)$ & & & Reference \\
\hline$T t$ & $27(54)$ & $25(50)$ & 0.4 & 0.8 & $1.08(0.46-2.42)$ \\
\hline$t t$ & $5(10)$ & $7(14)$ & & & $0.71(0.19-2.67)$ \\
\hline$P_{\text {HWE }}$ & 0.44 & 0.22 & & & \\
\hline
\end{tabular}

Confidence interval $(\mathrm{Cl})$, Odds ratio $(\mathrm{OR})$. Two sided Chi square test and odds ratio $95 \% \mathrm{Cl}$ test were used

Table 2: Genotype frequency of Apa I and Taq I among patients and controls. 


\begin{tabular}{|c|c|c|c|c|}
\hline Variables & $\begin{array}{c}\text { Patients } \\
(\mathbf{n = 5 0 )} \\
\mathbf{n}(\%)\end{array}$ & $\begin{array}{c}\text { Controls(n=50) } \\
\mathbf{n}(\mathbf{\%})\end{array}$ & $\mathbf{P}$ value & $\begin{array}{c}\text { OR } \\
(\mathbf{9 5 \%} \mathbf{C l})\end{array}$ \\
\hline Apa I Alleles & & & & \\
\hline$A$ & $48(96)$ & $43(86)$ & 0.81 & Reference \\
\hline$a$ & $20(60)$ & $28(56)$ & 0.68 & $0.95(0.49-1.85)$ \\
\hline Taq I Alleles & & & & \\
\hline$T$ & $45(90)$ & $43(86)$ & 0.53 & Reference \\
\hline$t$ & $32(64)$ & $32(64)$ & 1.0 & $0.95(0.60-1.50)$ \\
\hline
\end{tabular}

Confidence interval $(\mathrm{Cl})$, Odds ratio (OR). Two sided Chi square test and odds ratio $95 \% \mathrm{Cl}$ test were used

Table 3: Carriage of Apa I and Taq I alleles among patients and controls.

\begin{tabular}{|c|c|c|c|c|c|}
\hline Haplotype & Case \% & Control \% & Chi Square & P Value & $\begin{array}{c}\text { OR } \\
\text { (95\% Cl) }\end{array}$ \\
\hline$A T$ & 41 & 32 & 1.747 & 0.1862 & Reference \\
\hline$A t$ & 37 & 39 & 0.085 & 0.7708 & $0.74(0.38-1.41)$ \\
\hline$a T$ & 22 & 29 & 1.29 & 0.2561 & $0.59(0.28-1.21)$ \\
\hline
\end{tabular}

Two sided Chi square test was used. Confidence interval $(\mathrm{Cl})$, Odds ratio (OR). Two sided Chi square test and odds ratio $95 \% \mathrm{Cl}$ test were used

Table 4: Haplotype frequencies in patients and controls.

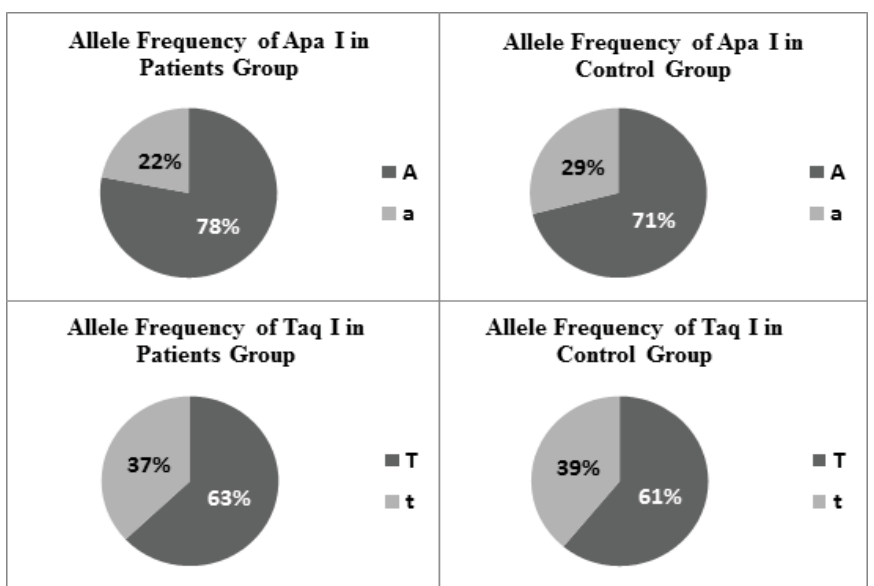

Figure 5: Pie charts showing Apa I and Taq I allele frequencies in diabetic and control groups.

in controls it represents $32 \%$. On the other hand $a T$ and At showed higher frequencies in controls (29\% and 39\%, respectively) than in patients ( $22 \%$ and $37 \%$ respectively). Chi square test $\left(\chi^{2}\right)$ didn't reveal statistically significant differences.

Linkage disequilibrium (LD) analysis shows that Apa I and Taq I SNPs of the VDR gene are in a single haplotype block as shown in Figure (6). The normalized correlation coefficient (D') equals 1 which signifies high LD between the two SNPs.

Different genotype combinations of Apa I and Taq I variants studied are shown in Table 5. Chi square test showed significant difference among genotype combinations in both diabetic and control groups $(P$ value $=0.02)$. The Genotypes AATt, AAtt, AaTT and aaTT were shown to be protective against T1D ( $P$ value of $O R=0.032,0.033$ and 0.002 ), respectively.

\section{Discussion}

In this study, the most frequent Apa I polymorphism in the control

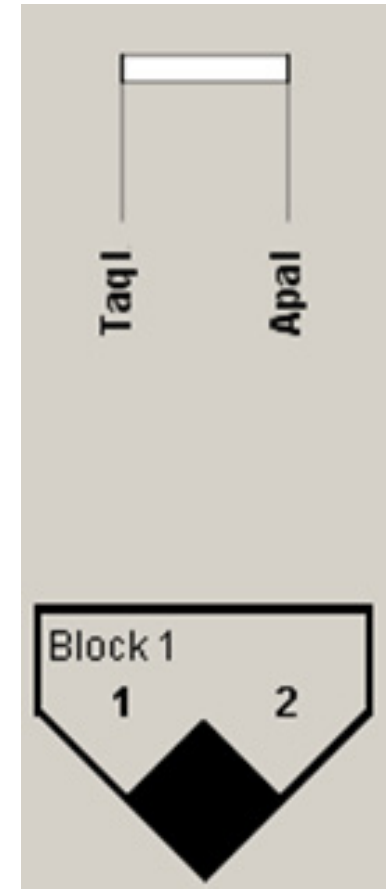

Figure 6: LD plot: The physical position of each SNP on the chromosome is shown above the plot as white bar. Black outline denotes haplotype block. Color intensity indicates value of D' as intensity of the grey scale refers to the its value. Greyscale inside the rhomboid shape ranges from white $\left(D^{\prime}=0\right)$ to Black $\left(D^{\prime}=1\right)$. Color of the rhombus shown indicates high value of the LD coefficient $\left(D^{\prime}=1\right)$.

group was $A A$. This result was inconsistent with several studies who reported $A a$ genotype as the most frequent genotype among Egyptian control subjects in their studies [18-20]. However in another study, genotype frequency of $A a$ and $A A$ were equal among an Egyptian control group [21].

The reported differences in genotype frequencies may be attributed to small sample sizes or ethnic differences. Iranian study found that genotype frequency of $A A$ and $A a$ were equal among an Iranian control group [22]. Studies reported that $A a$ is the predominant genotype in a Saudi and a Syrian populations, respectively [23,24]. Throughout different populations Aa was found to be the most frequent genotype in Taiwan [25], Hungary [26], Finland [7], Croatia [26], Italy [27] and Spain [28]. Study on Japanese population revealed that genotype frequencies of $A a$ and $a a$ were equal in the control group [29].

In the diabetic group, $A A$ genotype of Apa I polymorphism was the most frequent genotype. This frequency was consistent with the findings of Egyptian study [19]. In addition, our results are in agreement with the findings in Saudi [23], Croatian [30] and Italian populations [27]. On the other hand, the studies conducted on Taiwanese [25], Hungarian [26], Finnish [7], Spanish [28] and Iranian [22] populations differed with our results where $A a$ genotype was the most frequent.

Regarding genotype frequency of Taq I polymorphism in control group, our study found that Tt genotype was the most predominant. This result was consistent with two Egyptian studies [18,21]. However another two Egyptian studies reported that $T T$ was the most common genotype among control group $[19,20]$. Again, small sample sizes may 


\begin{tabular}{|c|c|c|c|c|c|c|}
\hline Genotype & $\begin{array}{c}\text { Patients } \\
\%\end{array}$ & $\begin{array}{c}\text { Controls } \\
\%\end{array}$ & $\mathbf{X}^{2}$ & $\boldsymbol{P}$ Value & $\begin{array}{c}\text { OR } \\
(\mathbf{9 5 \%} \text { Cl) }\end{array}$ & $\boldsymbol{P}^{\text {value }}$ \\
\hline AATT & 20 & 8 & 13.37 & $\mathbf{0 . 0 2}^{*}$ & Reference & \\
\hline AATt & 30 & 34 & & & $0.35(0.135-0.917)$ & $\mathbf{0 . 0 3 2}^{\boldsymbol{*}}$ \\
\hline AAtt & 10 & 14 & & & $0.28(0.090-0.905)$ & $\mathbf{0 . 0 3 3}^{\boldsymbol{1}}$ \\
\hline AaTT & 12 & 14 & & & $0.34(0.111-1.05)$ & 0.06 \\
\hline AaTt & 24 & 16 & & & $0.60(0.213-1.69)$ & 0.33 \\
\hline aaTT & 4 & 14 & & & $0.11(0.02-0.45)$ & $\mathbf{0 . 0 0 2}^{\boldsymbol{*}}$ \\
\hline
\end{tabular}

Confidence interval $(\mathrm{Cl})$, Odds ratio (OR). Two sided Chi square test and odds ratio $95 \% \mathrm{Cl}$ test were used. *: statistically significant $(p \leq 0.05)$

Table 5. Frequency of genotype combinations among patients and controls.

contribute to such discrepancies among genotype frequency of subjects drawn from the same population.

Ethnic differences could not be ruled out as cofounder of the reported differences. Studies carried out on normal Iranian [22] and Saudi [23] populations showed that $T T$ is the most frequent genotype. Syrian study showed that $T t$ is the most common genotype in normal Syrians [24]. Among other populations, several studies carried on normal subjects, showed that $T T$ is the most common genotype $[25,26,29]$. However, studies conducted on Germans [31], Croatians [32], Italians [27] and Spanish [28] populations found $T t$ to be the most frequent genotype.

For Taq I polymorphism, the most frequent genotype was $T t$ in the diabetic patients group in this study. These results are different from those reported for Egyptians [19]. On the other hand, Croatian [30], Italian [27] and Spanish [28] populations showed agreement with our results. However, Saudi [23], Iranian [22], Taiwanese [25], Hungarian [26], German [31] and Japanese [29] disagreed with our results. Different ethnic background in addition to environmental factors may contribute to the causes of such differences among various populations regarding allele and genotype frequencies.

In comparison between patients and controls in our study, genotype frequencies of $A A$ and $A a$ of Apa I variants and Tt for Taq I were observed to be higher in T1D patients than in the control group. On the other hand, $a a$ and $t t$ genotypes were shown to have higher frequencies in the control group which may give these genotypes a possible protective effect against T1D.

In the control group of our study, allele frequencies of Apa I polymorphism showed that $A$ allele was the most common representing $71 \%$. This result was consistent with results on Egyptians [18,20,21], Iranians [22], Syrians [24]. In other populations, most of the studies found that $A$ allele is the most frequent; Hungarian [26], Finnish [7], Croatian [30], Italian [27] and Spanish [28]. On the other hand, Taiwanese [25], Japanese [29] and Egyptians [19,23] found $a$ allele to be the most frequent in their studies.

In T1D patients of our study, Apa I polymorphism showed predominantly $A$ allele. Our results were, consistent with studies on Iranian [22] and Egyptian [19] populations. Similar results were reported for Croatian [30], Finnish [7] and Italian [27] populations. However, other studies disagreed with our findings and showed $a$ as the most frequent allele; studies on Taiwanese [25], Japanese [29], Germans [26] and Spanish [28].

For Taq I Polymorphism, our results showed that $T$ allele was the most common among control group representing $61 \%$. This result showed agreement with other studies on Egyptians conducted on healthy individuals [18-21]. Studies on Iranians [22], Saudi [23] and Syrians [24], reported that $T$ allele is predominant as well. In other populations, all compared studies were consistent with our results [25-31].

The most frequent allele regarding Taq I polymorphism among T1D patients was $T$ allele. Other results on Egyptians [19], Iranian [22] and Saudi [23] were consistent with our results. In Taiwanese [25], Japanese [29], Hungarian [26], German [31], Croatian [32], Italian [27] and Spanish [28] populations, the $T$ allele was predominant.

In our study, comparing patients to controls revealed that $A$ and $T$ alleles were more prevalent in patients than in controls on expense of $a$ and $t$ alleles which were observed to be higher in control group. This result may propose the possibility that $a$ and $t$ alleles have a protective role against T1D. The apparent discrepancies between our results and other studies could be due to ethnic differences and sample heterogeneity related to the distribution of VDR polymorphisms in these populations, as well as to interactions with other genetic or environmental factors involved in the pathogenesis of type 1 diabetes.

In this study, linkage disequilibrium (LD) analysis of VDR gene markers (Apa I and Taq I) showed that Apa I and Taq I are in strong linkage disequilibrium where $D^{\prime}=1$. This result is in concordance with studies conducted on German [14], British [33] and Egyptian [19] populations who reported a strong LD between Apa I, Bsm I and Taq I.

Haplotype analysis of Apa I and Taq I markers in T1D patient and control groups in our study, revealed that the most frequent haplotype in T1D patients was $A T$ (41\%) while in control group, At haplotype predominates (39\%). The affinity of $A$ to $T$ alleles increases in patients group resulted in increase of haplotype $A T$ on expense of $a T$ that decreases in patients. No significant difference was observed in haplotype distribution among patients and controls. This result is in disagreement with an Egyptian study that suggested an association between Apa I and Taq I haplotype and T1D in an Egyptian population [19]. A study conducted on 152 Caucasian families with at least one affected offspring with T1D revealed that haplotype At was preferentially transmitted to affected offspring which signified increased risk for T1D affection. In addition, haplotypes $A T$ and at were considered to be protective against T1D as they were preferentially not transmitted [14]. A study tested Apa I-Taq I haplotypes on 1811 British diabetic families and found no significant association between this haplotype and T1D [33].

Genotype combinations in our study showed that AATt, AAtt and aaTT had statistically significant protective effect against T1D. On the other hand, AATT and AaTt showed increased risk for T1D. No genotype combination analysis was done to Apa I and Taq I separately, however, a study showed that the genotype combination of Apa I-Bsm I and Taq I, $A a B b T t$, had a statistically significant protective effect against T1D among Italians [27]. These results are in contrast to our findings if we consider the two alleles AaTt.

In summation, populations from different ethnic backgrounds were reported to have an association between Apa I-Taq I VDR gene variations and T1D: Germans [14], Taiwanese [25], South Croatian [32] and Spanish [28]. However, other populations from also different ethnic backgrounds were reported to have no association: Southern Indians [34], Japanese [29], Hungarian [26], Finnish [7], Chilean [35], English [33], Portuguese [36] and South Croatian [37]. Conflicts in associations between VDR gene markers and T1D may be explained by the relatively small sample sizes, laboratory techniques, and different ethnic backgrounds. However, environmental factors disposing to body weight, and growth should be considered as likely candidates to affect the association between VDR polymorphism and development of T1D in different populations. 


\section{Conclusion}

1. The $A$ and $T$ alleles of the Apa I and Taq I VDR gene may predispose to the risk of T1D affection, whereas, $a$ and $t$ alleles may have a protective role against T1D.

2. Genotypes $A A$ and $A a$ of Apa I variants and Tt for Taq I may have a role in T1D pathogenesis, whereas, $a a$ and $t t$ genotypes may have a possible protective effect against T1D.

3. The combined genotypes AATt, AAtt and aaTT offer protection against T1D.

4. The haplotype $A T$ may be implicated in T1D risk, whereas, haplotypes $A t$ and $a T$ could have a possible protective effect against T1D.

\section{Conflicts of Interest}

Authors declare they have no conflicts of interest.

\section{Acknowledgement}

I deeply thank my colleague Dr. Eman Toraih, Lecturer of Medical Genetics Faculty of Medicine, Suez Canal University, Egypt, for her assistance in laboratory work and data analysis. I would like also to thank Dr. Hisham Daoud, Assistan Professor of Electrical Engineering, Canadian International College, Egypt, for his valuable help in data analysis.

\section{References}

1. Atkinson MA and Maclaren NK (1994) The pathogenesis of insulin-dependent diabetes mellitus. N Engl J Med 331: 1428-1436

2. Atlas ID (2013) Brussels, Belgium: The International Diabetes Federation. Int Diabetes Fed 50-78.

3. Steck AK, Rewers MJ (2011) Genetics of type 1 diabetes. Clin Chem 57: 176-185

4. Valdivielso JM, Fernandez E (2006) Vitamin D receptor polymorphisms and diseases Clin Chim Acta 371: 1-12.

5. Kulie T, Groff A, Redmer J, Hounshell J, Schrager S (2009) Vitamin D: an evidence-based review. J Am Board Fam Med 22: 698-706.

6. Kato S (2000) The function of vitamin D receptor in vitamin D action. J Biochem (Tokyo) 127: 717-722.

7. Turpeinen H, Hermann R, Vaara S, Laine AP, Simell O, et al. (2003) Vitamin $D$ receptor polymorphisms: no association with type 1 diabetes in the Finnish population. Eur J Endocrinol 149: 591-596.

8. Guo SW (2006) Meta-analysis of vitamin D receptor polymorphisms and type 1 diabetes: A huge review of genetic association studies. Am J Epidemiol164: 711-724.

9. http://www.ensembl.org/Homo_sapiens/Variation/Explore?db=core;g=EN SG00000111424; $\quad r=12: 133275309-133275309 ; v=r s 7975232 ; v d b=$ variation vf $=4764498$

10. http://www.ensembl.org/Homo sapiens/Variation/Explore?db=core;g=EN SG00000111424; $r=12: 133275309-133275309 ; v=r s 731236 ; v d b=$ variation; $v f=515885$

11. http://www.ncbi.nlm.nih.gov/nuccore/NG_008731.1

12. http://nc2.neb.com/NEBcutter $2 /$ enz.php? name $=8$ bff 40 f 7 \&enzname=Taql\&recpos $=248$

13. "http://nc2.neb.com/NEBcutter2/enz.php?name=8bff40f7-\&enzname=Apal\& recpos $=527$

14. Pani MA, Knapp M, Donner H, Braun J, Baur MP, et al. (2000) Vitamin D receptor allele combinations influence genetic susceptibility to type 1 diabetes in Germans. Diabetes 49: 504-507.

15. Blakemore Al, Cox A, Gonzalez AM, Maskill JK, Hughes ME, et al., (1996) Interleukin-1 receptor antagonist allele (ILIRN* 2 ) associated with nephropathy in diabetes mellitus. Hum. Genet 97: 369-374.

16. Syrjänen J, Hurme M, Lehtimäki T, Mustonen J, and Pasternack A (2002) "Polymorphism of the cytokine genes and IgA nephropathy. Kidney Int 61: 1079-1085.

17. Jalba MS, Rhoads GG, Demissie K, (2008) Association of codon 16 and codon 27 B2-adrenergic receptor gene polymorphisms with obesity: A meta-analysis. Obesity 16: 2096-2106.
8. Ismail S, Erfan M, EL-Salam MA, Kamal S, Ibrahim S, et al. (2011) Vitamin D receptor gene polymorphism and growth pattern in Egyptian rachitic children Life Sci J 8: 120-131.

19. Kamel MM, Fouad SA, Salaheldin O, Aeraa El (2014) Impact of vitamin D receptor gene polymorphisms in pathogenesis of Type-1 diabetes mellitus. Int J Clin Exp Med 7: 5505-5510.

20. Rizk MM, Zakaria NH, Elshazely WG (2014) Study of vitamin D receptor (VDR) gene polymorphisms among Egyptian cohort patients with different stages of colorectal cancer. J Cancer Ther 5: 253-263.

21. Abu el Maaty MA, Hassanein SI, Sleem HM, Gad MZ (2015) Vitamin D recepto gene polymorphisms (Taql and Apal) in relation to 25 -hydroxyvitamin $\mathrm{D}$ levels and coronary artery disease incidence. J. Recept. Signal Transduct 35: 391-395.

22. Bonakdaran S, Abbaszadegan MR, Dadkhah E, Khajeh-Dalouie M (2012) Vitamin $D$ receptor gene polymorphisms in type 1 diabetes mellitus: a new pattern from Khorasan province, Islamic Republic of Iran/Polymorphismes du gène du récepteur de la vitamine $D$ et diabète de type 1: un nouveau modèle dans la province de Khorasan (République islamique d'Iran). East Mediterr Health J 18: 614 .

23. El-Badrawy ES, Ibrahim ZS, Aziz A, Kamel MM, Shehab GM, et al. (2016) Association of vitamin $D$ receptors genes polymorphism (Apa I and Taq I) with type 1 diabetes in Saudi Arabia (KSA) 581: 43-47.

24. Haddad S (2014) Vitamin-D receptor (VDR) gene polymorphisms (Taq-I \& Apa-I) in Syrian healthy population. Meta Gene 2: 646-650.

25. Chang TJ, Lei HH, Yeh JI, Chiu KC, Lee KC, et al. (2000) Vitamin D recepto gene polymorphisms influence susceptibility to type 1 diabetes mellitus in the Taiwanese population. Clin Endocrinol (Oxf.) 52: 575-580.

26. Gyorffy B, Vásárhelyi B, Krikovszky D, Madácsy L, Tordai A, et al. (2002) Gender-specific association of vitamin D receptor polymorphism combinations with type 1 diabetes mellitus. Eur J Endocrinol 147: 803-808.

27. Bianco MG, Minicucci L, Calevo MG, Lorini R (2004) Vitamin D receptor polymorphisms: are they really associated with type 1 diabetes? Eur. J Endocrinol 151: 641 .

28. Pedro JS, Bilbao JR, Perez de Nanclares G, Vitoria JC, Martul P, et al. (2005) Heterogeneity of vitamin $D$ receptor gene association with celiac disease and type 1 diabetes mellitus. Autoimmunity 38: 439-444.

29. Yokota I, Satomura S, Kitamura S, Taki Y, Naito E, et al. (2002) Association between vitamin $\mathrm{D}$ receptor genotype and age of onset in juvenile Japanese patients with type 1 diabetes. Diabetes Care 25: 1244-1244.

30. Škrabić V, Zemunik T, Šitum M, and Terzić J (2003) Vitamin D recepto polymorphism and susceptibility to type 1 diabetes in the Dalmatian population. Diabetes Res Clin Pract 59: 31-35.

31. Fassbender WJ, Goertz B, Weismüller K, Steinhauer B, Stracke H, et al. (2002) VDR gene polymorphisms are overrepresented in German patients with type 1 diabetes compared to healthy controls without effect on biochemical parameters of bone metabolism. Horm Metab Res Horm Stoffwechselforschung Horm Metab 34: 330-337.

32. Škrabić V, Zemunik T, Šitum M, Terzić J (2003) Vitamin D receptor polymorphism and susceptibility to type 1 diabetes in the Dalmatian population. Diabetes Res Clin Pract 59: 31-35.

33. Nejentsev S, Godfrey L, Snook H, Rance H, Nutland S, et al. (2004) Comparative high-resolution analysis of linkage disequilibrium and tag single nucleotide polymorphisms between populations in the vitamin $D$ receptor gene. Hum Mol Genet 13: 1633-1639.

34. McDermott MF, Ramachandran A, Ogunkolade BW, Aganna E Curtis D, et al. (1997) Allelic variation in the vitamin $D$ receptor influences susceptibility to IDDM in Indian Asians. Diabetologia 40: 971-975.

35. Angel B, Santos JL, Carrasco E, Albala C, Pérez-Bravo F (2004) Vitamin D receptor polymorphism and susceptibility to type 1 diabetes in Chilean subjects: a case-parent study. Eur J Epidemiol 19: 1085-1087.

36. Lemos MC, Fagulha A, Coutinho E, Gomes L, Bastos M, et al. (2008) Lack of association of vitamin $\mathrm{D}$ receptor gene polymorphisms with susceptibility to type 1 diabetes mellitus in the Portuguese population. Hum Immunol 69 : 134-138.

37. Boraska V, Škrabić V, Zeggini E, Groves CJ, Buljubašić M, et al. (2008) Familybased analysis of vitamin $\mathrm{D}$ receptor gene polymorphisms and type 1 diabetes in the population of South Croatia. J Hum Genet 53: 210-214. 